\title{
CRP Genotypes Predict Increased Risk to Co-Present with Low Vitamin D and Elevated CRP in a Group of Healthy Black South African Women
}

\author{
Pieter H. Myburgh ${ }^{1, *}$ (D) G. Wayne Towers ${ }^{2}$, Iolanthé M. Kruger ${ }^{2}$ (D) and \\ Cornelie Nienaber-Rousseau ${ }^{1}$ iit \\ 1 Centre of Excellence for Nutrition, North-West University, 11 Hoffman Street, Potchefstroom 2520, \\ North West Province, South Africa; cornelie.nienaber@nwu.ac.za \\ 2 Africa Unit for Transdisciplinary Health Research (AUTHeR), North-West University, 11 Hoffman Street, \\ Potchefstroom 2520, North West Province, South Africa; wayne.towers@nwu.ac.za (G.W.T.); \\ lanthe.kruger@nwu.ac.za (I.M.K.) \\ * Correspondence: 20266677@nwu.ac.za; Tel.: +27-18-299-4169
}

Received: 13 November 2017; Accepted: 30 December 2017; Published: 10 January 2018

\begin{abstract}
Low 25-hydroxyvitamin D (25(OH)D) and elevated C-reactive protein (CRP) concentrations are independently associated with adverse health outcomes, including cardiovascular disease (CVD). Although an inverse association between these factors has been described, the underlying mechanisms remain unknown. We postulate that environment-gene interactions, through which $25(\mathrm{OH}) \mathrm{D}$ interacts with single nucleotide polymorphisms (SNPs) within the CRP gene, modulate CRP; that certain CRP genotypes predispose individuals to a co-phenotype of low $25(\mathrm{OH}) \mathrm{D}$ and elevated CRP concentrations; and that this co-phenotype is associated with higher CVD risk. Twelve CRP SNPs were genotyped, and both 25(OH)D and CRP were quantified, in 505 black South African women. Alarmingly, $66 \%$ and $60 \%$ of the women presented with deficient/insufficient $25(\mathrm{OH}) \mathrm{D}$ and elevated CRP concentrations, respectively. CRP concentrations were higher in individuals with lower $25(\mathrm{OH}) \mathrm{D}$ concentrations. However, no $25(\mathrm{OH}) \mathrm{D}-C R P$ genotype interactions were evident. Several genotypes were associated with an altered risk of presenting with the co-phenotype, indicating a genetic predisposition. Women presenting with this co-phenotype had higher blood pressure and increased anthropometric measures, which may predispose them to develop CVD. We recommend increasing vitamin D fortification and supplementation efforts to reduce inflammation among black women with vitamin D deficiency, thereby possibly curbing diseases contingent on the co-phenotype described here.
\end{abstract}

Keywords: 25-hydroxyvitamin D; 25(OH)D; calcidiol; calciferol; C-reactive protein; nutrigenetics; single nucleotide polymorphisms; SNPs; Tswana

\section{Introduction}

Cardiovascular disease (CVD) is the leading cause of mortality, with $80 \%$ of the global burden carried by developing countries [1]. In South Africa, at the time of this study, one third of all deaths were attributable to CVD [2]. Since then, an increase in CVD-related deaths has been reported [3]. The role of chronic inflammation in the etiology of CVDs has recently come to the fore. Although the inflammatory response is regarded as crucial for survival, dysregulation of this process has detrimental effects, including the development of CVDs $[4,5]$.

Several biochemical markers of inflammation have been identified, including tumor necrosis factor- $\alpha$, interleukin 1 (IL-1) and 6 (IL-6), and C-reactive protein (CRP). CRP is by far the most widely investigated biomarker of low-grade systemic inflammation, as it has a stable half-life with 
well-established associations with disease, and has known cut-off values [6]. People with a basal CRP concentration greater than $3 \mathrm{mg} / \mathrm{L}$ are at higher risk of experiencing cardiovascular events [7]. Circulating CRP concentrations can be influenced by demographic factors (age, sex, and ethnicity) as well as environmental and behavioral factors (alcohol intake, diet, socio-economic status, and tobacco use) [8-12]. Among dietary factors, an inverse association between vitamin D and CRP has been established [13,14]. A recent meta-analysis [15] indicated that vitamin D supplementation decreased CRP concentrations by $1.08 \mathrm{mg} / \mathrm{L}(95 \%$ confidence interval (CI), $-2.13,-0.03)$, while those with baseline CRP levels of $>5 \mathrm{mg} / \mathrm{L}$ registered a more significant reduction of $2.21 \mathrm{mg} / \mathrm{L}$ (95\% CI, -3.5 , $-0.92)$. Various genetic factors have been reported to affect CRP concentrations, with twin and family studies indicating substantial heritability of between $35 \%$ and $40 \%$ [16]. Furthermore, interactions have been observed between CRP single nucleotide polymorphisms (SNPs) and dietary intake influencing circulating CRP concentrations [17]. In contrast, infection with the human immune deficiency virus (HIV) is not associated with CRP [18], an observation re-established by the present study.

Black individuals tend to have higher circulating CRP concentrations than those from other groups [19]. African Americans, included in a meta-analysis, presented with CRP concentrations of $2.6 \mathrm{mg} / \mathrm{L}$ compared to $2.51 \mathrm{mg} / \mathrm{L}$ in Hispanics, $2.03 \mathrm{mg} / \mathrm{L}$ in white Americans, and $1.01 \mathrm{mg} / \mathrm{L}$ in East Asians [20]. Elevated CRP concentrations are also typical in black South Africans [17]; comparisons show them to be higher $(3.61 \mathrm{mg} / \mathrm{L})$ than those of their white $(1.13 \mathrm{mg} / \mathrm{L})$ compatriots [21].

Ethnicity also affects vitamin D status. Darker skin (type V and VI skin on the Fitzpatrick scale [22]), as observed in African individuals, seems to have originated in persons living in areas with high ultra-violet (UV) radiation (UVR) [23]. Even though it is a photoprotective mechanism, darker skin reduces the synthesis of vitamin D [24] as measured by circulating 25-hydroxyvitamin D $(5(\mathrm{OH}) \mathrm{D})$, or calcidiol, concentrations. Darker-skinned humans require approximately six times more UVR exposure than their fairer-skinned counterparts to produce similar amounts of vitamin D [25]. South Africa, ranging between the $\sim 22^{\circ}$ and $34^{\circ}$ southern latitudes, experiences relatively intense UVR, although not as extreme as at the equator [25]. Black South Africans present with lower 25(OH)D concentrations than dark-skinned people living closer to the equator [26]. The rapid urbanization observed in most African countries, resulting in reduced exposure to UVR, has been proposed as a major contributing factor to the low $25(\mathrm{OH}) \mathrm{D}$ status observed in black Africans [27]. Other risk factors associated with low 25(OH)D status include age, obesity, HIV infection, and smoking [28-30].

Apart from influencing inflammation, vitamin $\mathrm{D}$ itself is related to disease risk. $25(\mathrm{OH}) \mathrm{D}$ has preventive effects on a range of chronic maladies, including CVD [31]. Two meta-analyses found an increase in the risk of developing ischemic heart disease, as well as an augmented risk of symptomatic ischemic stroke for the participants in the lowest quartiles of 25(OH)D concentrations [32,33]. Another meta-analysis reported an inverse association between $25(\mathrm{OH}) \mathrm{D}$ concentrations and the risks associated with all-cause mortality (relative risk (RR) of 1.35 (1.22-1.49)) and CVD (RR: 1.35 (1.13-1.61)) [34].

As elevated concentrations of CRP are associated with increased CVD risk, whereas CVD risk is reduced with elevated levels of $25(\mathrm{OH}) \mathrm{D}$, a hypothesis has been proposed that $25(\mathrm{OH}) \mathrm{D}$ might influence CRP [35]. However, there is no evidence of a direct pathway by which $25(\mathrm{OH}) \mathrm{D}$ or its metabolized product, 1,25-dihydroxyvitamin D (or calcitriol), affects the expression of CRP (or vice versa) [13]. Vitamin D-mediated mechanisms for a reduction in vascular damage have been proven experimentally, with the inhibition of cholesterol uptake by macrophages and the suppression of the renin gene [14]. In vitro studies have also described the diminished production of IL-6 in monocytes treated with vitamin $\mathrm{D}_{3}$ (cholecalciferol, or calciol) compared to untreated cells [35]. IL-6, synthesized by macrophages, is transported to the liver, where the transcriptional activation of $C R P$ is mediated via Signal Transducer and Activator of Transcription factor 3 (STAT3) [36,37]. These physiological mechanisms might, therefore, act as potential indirect pathways by which vitamin D and its metabolites could influence CRP concentrations. Thus, having elevated CRP as well as low $25(\mathrm{OH}) \mathrm{D}$ concentrations, which are both independently associated with increased CVD risk, may exacerbate disease development. 
Because black individuals tend to be predisposed to lower $25(\mathrm{OH}) \mathrm{D}$ and higher CRP concentrations, investigations that involve this particular population will increase the chance of observing sufficient numbers of the phenotypes of interest. An inverse association between 25(OH)D and inflammation has been described, but the underlying mechanisms remain unknown [13]. Moreover, it has to be established whether vitamin D status influences CRP differently in individuals harboring specific CRP genotypes in modulating CRP concentrations. We determined whether vitamin $\mathrm{D}$ status possibly interacts with these $C R P$ genotypes to affect the CRP concentrations. In addition, we tested whether CRP SNPs affected 25(OH)D concentrations. Studying environment-gene interactions is important, as identifying these interactions and modifying behaviors accordingly could improve health outcomes. Furthermore, we determined whether specific CRP genotypes predispose individuals to a co-phenotype of low $25(\mathrm{OH}) \mathrm{D}$ and elevated CRP, as well as whether this co-phenotype is associated with a higher CVD risk in black South African women. This research is important, because unraveling possible mechanisms for the observed relationship between vitamin D and CRP leads to a better understanding of the foundation of this relationship and paves the way for designing targeted approaches to treat the corresponding elevated CRP concentrations and low 25(OH)D concentrations in black individuals. This research might also indicate whether efforts to increase responsible sunlight exposure and include more vitamin-D-rich foods in their diet are, and/or whether supplementation with vitamin D is, desirable for black South African women.

\section{Materials and Methods}

\subsection{Ethical Considerations}

For this cross-sectional investigation, we used data collected for the South African arm of the Prospective Urban and Rural Epidemiology (PURE-SA) study, at baseline (2005). Ethical approval, in accordance with the Declaration of Helsinki as revised in 2004 [38], was obtained for the larger study from the Health Research Ethics Committee of the Faculty of Health Sciences, North-West University (NWU-HREC, ethics number: 04M10). Ethical approval was also granted for this affiliated study (ethics number: NWU-00004-17-A1). Goodwill permission was granted to the PURE study by mayors, household heads, community leaders of the communities included, and tribal chiefs before the research started. Participants were well-advised about the research project and were asked to sign an informed consent form, after sufficient time for reflection, to indicate their agreement to take part in the study. Subjects could withdraw at any time, or withhold any information they were not comfortable sharing.

\subsection{Research Design and Study Population}

The PURE-SA study aims to investigate the development of chronic lifestyle diseases, with a focus on CVDs, by stratifying populations at different levels of urbanization [39]. Four communities were selected in 2005 in South Africa, based on their degree of urbanization, and grouped into either being urban (Location A) or rural (Location B). The initial sampling strategy is explained elsewhere [40].

Eligible participants were all apparently healthy adults who were older than 30 years. On the day of enrollment, individuals with elevated body temperatures (above $38{ }^{\circ} \mathrm{C}$ ) were excluded to reduce the number of volunteers with acute infections. Further exclusion criteria were that potential volunteers were not allowed to use chronic medication, to have any known lifestyle disease, be pregnant or lactating, or to have a known infection, such as tuberculosis-causing agents and/or the human immune deficiency virus (HIV) (details in [40]). Sampling was conducted between August and November 2005, which is late winter to late spring in the southern hemisphere. Of 6000 individuals screened, 2010 were included at baseline. The $25(\mathrm{OH}) \mathrm{D}$ status of a subset of 660 randomly selected women was determined, because of constrained budgets and the fact that women are more likely to develop skeletal disorders associated with low 25(OH)D status. 


\subsection{Biochemical and Blood Pressure Measurements}

Fasting participants, defined as sans food and beverages (water permitted) from the evening before enrollment, arrived at the study site, upon which professional nurses obtained blood samples. Blood tubes were centrifuged at $2000 \times g$ for $15 \mathrm{~min}$ at $10{ }^{\circ} \mathrm{C}$. Plasma, serum, and buffy-coat were aliquoted and snap-frozen on dry-ice pellets before storage at $-70^{\circ} \mathrm{C}$. Serum high-sensitivity CRP concentrations were measured on a Sequential Multiple Analyzer Computer using a particle-enhanced immunoturbidometric assay (Konelab TM auto analyzer, Thermo Fisher Scientific, Vantaa, Finland). Total 25(OH)D (sum of $\mathrm{D}_{2}$ and $\mathrm{D}_{3}$ ) in serum was quantified using a Roche Elecsys 2010 COBAS system (functional sensitivity: $10.0 \mathrm{nmol} / \mathrm{L}$; Roche Diagnostics, Indianapolis, IN, USA). Lipograms, including high-density lipoprotein cholesterol, triglycerides, and total cholesterol, were performed using a Konelab 20i auto analyzer (Thermo Fisher Scientific, Vantaa, Finland). The Friedewald equation was used to calculate the low-density lipoprotein cholesterol (LDL-c) in those with triglyceride concentrations below $400 \mathrm{mg} / \mathrm{dL}$ [41]. Research nurses-trained in voluntary counseling and the testing of HIV, adhering to the UNAIDS/WHO policy statement on HIV testing as well as the protocols set by the National Department of Health of South Africa-gave all participants pre-test counseling. Volunteers could then decide whether they wanted to be tested, with specific signed informed consent obtained for HIV testing after pre-test counseling. HIV determination was conducted using a rapid First Response HIV 1-2.O card test (Transnational Technologies Inc., PMC Medical, Nani Daman, India). Persons testing positive were re-tested using a second card test, developed by Pareeshak (BHAT Bio-Tech, Bangalore, India) to affirm HIV status. All participants, irrespective of their HIV status, were given post-test counseling individually. Blood pressure was measured in duplicate with an Omron automatic digital blood pressure monitor (Omron HEM-757) after $5 \mathrm{~min}$ of sitting in a calm environment.

\subsection{Anthropometric Measurements}

Body weights $(\mathrm{kg})$ were measured twice on calibrated and tared scales, with the mean recorded, while participants were lightly clothed and their arms hanging freely at their sides. Heights $(\mathrm{cm})$, with volunteers' heads in the Frankfort plane, bodies fully extended while inhaling, were measured twice to the nearest $10 \mathrm{~mm}$, using stadiometers, and the mean was reported in meters. Body mass index was computed as $\mathrm{kg} / \mathrm{m}^{2}$.

\subsection{Factors Pertaining to Lifestyle}

Participants responded to various interviewer-administered questionnaires in a language of their choice. These test instruments included questions on medical history and tobacco use. Nutritional information from the previous 30 days was obtained using validated, interviewer-based quantitative food frequency questionnaires (qFFQs) and employing food portion books standardized for the population under investigation [42]. qFFQs' data were entered into FoodFinder 3 (Medical Research Council, Tygerberg, South Africa) and analyzed by the Medical Research Council of South Africa for nutrient content.

\subsection{Genetic Analyses}

Determination of the genotypes via a BeadXpress analysis was performed by the National Health Laboratory Service located at the University of the Witwatersrand, Johannesburg. For details on the genetic analyses, please refer to Nienaber-Rousseau et al. [17].

\subsection{Environmental Data}

Locations A and B were compared using the means of data from 1 August (late winter) to 1 December 2005 (late spring). Environmental factors were investigated using satellite data obtained 
from an online repository, Giovanni [43]. Average mean temperature, UV index, erythemal dose rate, and total ozone column were downloaded as Google Earth data files (.kmz files).

\subsection{Statistical Analyses}

As previously mentioned, $25(\mathrm{OH}) \mathrm{D}$ concentrations were available for 660 randomly selected women. Only individuals for whom $25(\mathrm{OH}) \mathrm{D}$ concentrations, CRP concentrations, $C R P$ genetic data, and all anthropometric markers were available were included in our statistical analyses $(n=534)$. Furthermore, women with $25(\mathrm{OH}) \mathrm{D}$ or natural log-transformed $(\mathrm{ln}) \mathrm{CRP}$ concentrations greater than 5 standard deviations were excluded as outliers. The final number of participants was 505 . Statistical analyses were conducted in R [44].

Numeric variables were visually inspected for normality as well as measures of skewness. Non-parametric variables (CRP) were log-transformed, yet still reported as median and interquartile ranges. Women were grouped as two phenotypes: the case phenotype including individuals with deficient/insufficient 25(OH)D ( $<75 \mathrm{nmol} / \mathrm{L})$ and elevated CRP $(>3 \mathrm{mg} / \mathrm{L})$, and a control phenotype consisting of the remaining volunteers. Pairwise comparisons using the Wilcoxon ranked-sum test were performed to identify significant differences in stratified continuous variables. Comparative tables were created with the compare Groups library in R [45] using non-parametric methods. Spearman correlations were used for testing associations between numeric variables. Multivariate linear models predicting $\operatorname{lnCRP}$ concentrations from continuous $25(\mathrm{OH}) \mathrm{D}$ values were constructed using backward step-wise linear regressions and evaluated based on the Akaike Information Criterion (AIC). Adherence to Hardy-Weinberg equilibrium (HWE) was tested by a chi-squared $\left(\chi^{2}\right)$ test using SNPassoc, and linkage disequilibrium (LD) was calculated using the LDheatmap library of the R package.

Variables identified in regression analyses were evaluated for co-linearity. Possible environment-SNPs interaction was determined using SNPassoc [46] while including covariates obtained from the linear regression model. To determine whether CRP SNPs influence vitamin D status, $25(\mathrm{OH}) \mathrm{D}$ was used as the dependent variable. To evaluate the risk associated with certain CRP SNPs to present with the phenotype of low $25(\mathrm{OH}) \mathrm{D}$ combined with elevated CRP concentrations, the case and control phenotypes were entered as dependent variables.

Where applicable, $p$-values were adjusted using the methods suggested by Bonferroni. Significance was defined as an $\alpha$ level of 0.05 .

\section{Results}

\subsection{Association of 25(OH)D Concentrations/Status with Circulating CRP Concentrations}

Median concentrations for 25(OH)D and CRP were $68.2 \mathrm{nmol} / \mathrm{L}$ and $4.13 \mathrm{mg} / \mathrm{L}$, respectively, indicating that the $25(\mathrm{OH}) \mathrm{D}$ status of the women in our cohort was insufficient, while they also presented with elevated inflammation based on CRP. CRP concentrations decreased across increasing 25(OH)D categories, with the median CRP concentration being significantly lower in the sufficient $25(\mathrm{OH}) \mathrm{D}$ group compared to both the deficient and insufficient subdivisions (Figure 1). The largest variability in CRP concentrations was observed for those in the $25(\mathrm{OH}) \mathrm{D}$-deficient category, with decreasing variability in the insufficient and sufficient groups. In the population investigated, $42 \%$ $(n=216)$ of individuals presented with both $25(\mathrm{OH}) \mathrm{D}$ concentrations lower than $75 \mathrm{nmol} / \mathrm{L}$ and elevated CRP concentrations above $3 \mathrm{mg} / \mathrm{L}$ (case phenotype).

In Table 1, we have summarized the demographic characteristics of the case and control phenotypes: $25(\mathrm{OH}) \mathrm{D}$ concentrations decreased with age. The distribution between rural and urban cases and controls was similar. In addition, the environmental exposure that could have influenced vitamin D status did not differ between the rural or urban areas. Individuals representing the case phenotype were significantly older. Similar distributions were also observed in respect of smoking and HIV status. The median dietary intake of vitamin D sources did not differ for the two groups either. 


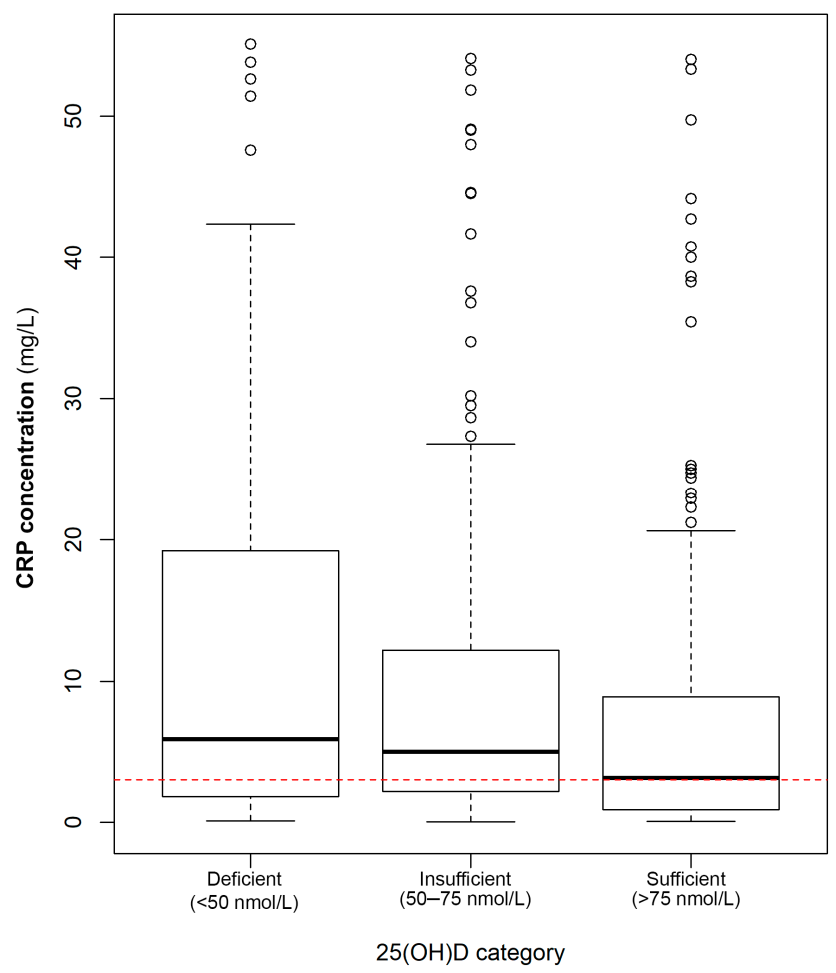

Figure 1. Median C-reactive protein (CRP) concentrations across different categories of 25(OH)D status $(p=0.001)$. Pairwise Wilcoxon ranked-sum test with Bonferroni adjustment revealed that women with sufficient $25(\mathrm{OH}) \mathrm{D}$ concentrations had significantly lower CRP concentrations than those with deficient or insufficient $25(\mathrm{OH}) \mathrm{D}$. Outliers depicted as open circles. The red dashed line indicates the cut-off value for CRP concentrations with elevated CRP being greater than $3 \mathrm{mg} / \mathrm{L}$.

Table 1. Comparisons of demographical and biochemical factors in the cohort stratified by control and case phenotypes.

\begin{tabular}{cccc}
\hline Variable & Controls $(\boldsymbol{n}=\mathbf{2 8 9}, \mathbf{5 7 . 2} \%)$ & Cases $(\boldsymbol{n}=\mathbf{2 1 6}, \mathbf{4 2 . 8} \%)$ & $p$-Value \\
\hline Urban/Rural & $144(49.8 \%) / 145(50.2 \%)$ & $126(58.3 \%) / 90(41.7 \%)$ & $N S$ \\
Age (years) & $53.0(49.0 ; 59.0)$ & $56.0(51.0 ; 63.0)$ & $<0.001$ \\
\hline Smoking status: & $6(2.10 \%) / 138(48.3 \%) / 142(49.7 \%)$ & $7(3.24 \%) / 96(44.4 \%) / 113(52.3 \%)$ & \multirow{2}{*}{$N S$} \\
\hline Former/Current/Abstainer & $26(9.03 \%) / 262(91.0 \%)$ & $15(6.98 \%) / 200(93.0 \%)$ & $N S$ \\
\hline HIV positive/negative & $2.00(1.02 ; 3.30)$ & $2.05(1.02 ; 3.66)$ & $N S$ \\
Vitamin D intake $(\mu \mathrm{\mu g} /$ day) & $64(23.0 \%) / 214(77.0 \%)$ & $37(17.2 \%) / 178(82.8 \%)$ & $N S$ \\
Menorhea/Amenorhea & &
\end{tabular}

Data presented as median (25th and 75th percentiles) for continuous data and number of observations (percentage) for categorical data. Abbreviations: 25(OH)D, 25-hydroxyvitamin D; HIV, human immune deficiency virus; NS, not significant $(p>0.05)$.

Differences in CVD risk markers between the two phenotypes are presented in Table 2. Those representing the control phenotype had lower blood pressure. However, heart rate was similar in the two groups. Anthropometric markers indicated that cases had significantly higher body weight and increased waist circumference. More obese individuals were also observed in the case phenotype. HDL-c was significantly higher in the control group; however, after adjusting for age, waist circumference, and LDL-c, the significance was eliminated. Furthermore, no statistical differences were observed for LDL-c, triglycerides, or energy intake, although energy intake was lower for the controls than for the case phenotypes. 
Table 2. Markers of cardiovascular disease (CVD) risk among the control and case phenotypes.

\begin{tabular}{|c|c|c|c|c|c|}
\hline \multicolumn{2}{|c|}{ Variable } & Controls $(n=289,57.2 \%)$ & Cases $(n=216,42.8 \%)$ & $p$-Value & Adjusted $p$-Value \\
\hline \multicolumn{2}{|c|}{ Systolic blood pressure $(\mathrm{mmHg})$} & $133(118 ; 148)$ & $138(124 ; 159)$ & $<0.001$ & $<0.01$ \\
\hline \multicolumn{2}{|c|}{ Diastolic blood pressure (mmHg) } & $87.0(78.0 ; 96.0)$ & $91.0(83.8 ; 101)$ & $<0.001$ & $<0.01$ \\
\hline \multicolumn{2}{|c|}{ Heart rate $(\mathrm{BPM})$} & $73.0(65.0 ; 83.0)$ & $72.0(63.0 ; 85.0)$ & NS & NS \\
\hline \multicolumn{2}{|c|}{ Waist circumference $(\mathrm{cm})$} & $79.3(70.8 ; 87.7)$ & $86.4(74.8 ; 95.5)$ & $<0.001$ & $<0.001$ \\
\hline \multicolumn{2}{|c|}{ Hip circumference $(\mathrm{cm})$} & $98.0(89.5 ; 106)$ & $106(94.1 ; 119)$ & $<0.001$ & 0.01 \\
\hline \multicolumn{2}{|c|}{ WHR } & $0.81(0.76-0.87)$ & $0.81(0.76-0.86)$ & NS & NS \\
\hline \multicolumn{2}{|c|}{ Weight (kg) } & $60.2(52.1 ; 72.8)$ & $72.0(56.5 ; 85.5)$ & $<0.001$ & $<0.01$ \\
\hline \multicolumn{2}{|c|}{$\operatorname{BMI}\left(\mathrm{kg} / \mathrm{m}^{2}\right)$} & $24.7(21.3 ; 29.0)$ & $29.9(23.3 ; 35.2)$ & $<0.001$ & $<0.001$ \\
\hline \multirow{4}{*}{ BMI category } & Underweight & $29(10.0 \%)$ & $22(10.2 \%)$ & \multirow{4}{*}{$<0.001$} & \multirow{4}{*}{$<0.001$} \\
\hline & Healthy & $122(42.2 \%)$ & $45(20.8 \%)$ & & \\
\hline & Overweight & $80(27.7 \%)$ & $42(19.4 \%)$ & & \\
\hline & Obese & $58(20.1 \%)$ & $107(49.5 \%)$ & & \\
\hline \multicolumn{2}{|c|}{ Total cholesterol (mmol/L) } & $5.21(4.38 ; 6.33)$ & $5.30(4.52 ; 6.20)$ & NS & NS \\
\hline \multicolumn{2}{|c|}{ High-density lipoprotein cholesterol (mmol/L) } & $1.48(1.14 ; 1.92)$ & $1.36(1.07 ; 1.76)$ & 0.03 & NS \\
\hline \multicolumn{2}{|c|}{ Low-density lipoprotein cholesterol $(\mathrm{mmol} / \mathrm{L})$} & $3.34(2.64 ; 4.23)$ & $3.58(2.69 ; 4.41)$ & NS & NS \\
\hline \multicolumn{2}{|c|}{ Triglycerides $(\mathrm{mmol} / \mathrm{L})$} & $1.22(0.90 ; 1.79)$ & $1.32(0.92 ; 1.78)$ & NS & NS \\
\hline \multicolumn{2}{|c|}{ Dietary intake $(\mathrm{kJ})$} & $6620(5056 ; 9265)$ & $7432(5294 ; 9283)$ & NS & NS \\
\hline
\end{tabular}

Adjusted for age, waist circumference, and LDL-c. Abbreviations: BMI, body mass index; BPM, beats per minute; CRP, C-reactive protein; $\mathrm{mmHg}$, millimeters of mercury; WHR, waist hip ratio. Data presented as median (25th and 75th percentiles) for continuous data and number of observations (percentage) for categorical data. BMI categories' cut-off values: Underweight $<18.5 \mathrm{~kg} / \mathrm{m}^{2}$; healthy $18.5-24.9 \mathrm{~kg} / \mathrm{m}^{2}$; overweight $24.9-29.9 \mathrm{~kg} / \mathrm{m}^{2} ;$ obese $>29.9 \mathrm{~kg} / \mathrm{m}^{2}$. Values presented in accordance with the International System of Units: to convert kJ to Cal multiply by 0.24 .

\subsection{Quantification of the Associations of 25(OH)D with CRP Concentrations}

Spearman correlation analyses (results not shown) revealed that $25(\mathrm{OH}) \mathrm{D}$ was inversely, albeit weakly $(\varrho>-0.20 ; p \leq 0.05)$, associated with age. No other factors were associated with 25(OH)D with a correlation greater than 0.20 , so that these are not reported here except for the correlation with CRP presented later. CRP was moderately associated with anthropometric markers (all $\varrho>0.30 ; p<0.05$ ) and lipid profile markers of which LDL-c $(\varrho=0.13 ; p<0.05)$ presented with the strongest correlation. Similar to vitamin D status, other variables did not correlate strongly with CRP even though these correlations were statistically significant.

A weak, yet significant, negative correlation was observed between $25(\mathrm{OH}) \mathrm{D}$ and CRP $(\varrho=-0.15$; $p<0.05)$. Converting $25(\mathrm{OH}) \mathrm{D}$ from $\mathrm{nmol} / \mathrm{L}$ to $\mathrm{mg} / \mathrm{L}$, using a conversion factor of 0.0004 (Equation (1)), indicated that a one-unit increase in $25(\mathrm{OH}) \mathrm{D}$ was associated with a $0.15 \mathrm{mg} / \mathrm{L}$ decrease in CRP concentration. Vitamin D intake did not correlate with 25(OH)D or CRP concentrations.

$$
\begin{gathered}
1 \mathrm{nmol} / \mathrm{L} 25(\mathrm{OH}) \mathrm{D}=0.4 \mathrm{ng} / \mathrm{mL} 25(\mathrm{OH}) \mathrm{D}=0.0004 \mathrm{mg} / \mathrm{L} 25(\mathrm{OH}) \mathrm{D} \\
0.0004 \mathrm{mg} / \mathrm{L} 25(\mathrm{OH}) \mathrm{D} \equiv-0.15(\mathrm{CRP}) \mathrm{mgL}
\end{gathered}
$$

The linear relationship between $25(\mathrm{OH}) \mathrm{D}$ as a factor influencing $\operatorname{lnCRP}$ concentrations was modelled in two ways: for the first model, we adjusted for age; and in the second, we adjusted for age, anthropometrical marker (see discussion below), and LDL-c. These covariates were chosen owing to the likelihood of these variables influencing the model based on their previous association with CRP concentrations, as well as having the lowest AIC score. As there is a large degree of co-linearity between anthropometric markers, each marker (i.e., BMI, waist and hip circumference, and weight) was entered into the model separately, and models were evaluated based on their resulting AIC value. The lowest AIC value was observed for waist circumference and LDL-c; therefore, these markers were used as a proxy for all other anthropometric and lipid profile markers, respectively. Dietary sources of vitamin D did not affect the model $(p>0.05)$. The unadjusted model (Model 1 ) accounted for $2.1 \%$ of the variance of $\operatorname{lnCRP}$ (calculated from adjusted $\mathrm{R}^{2}$ values; $p=0.001$ ). For Model 1, a $1.1 \%$ reduction in CRP concentration (converting lnCRP to CRP by using $\left.\left(\mathrm{e}^{\beta}-1\right) \times 100\right)$ ) for each $1 \mathrm{nmol} / \mathrm{L}$ increase in $25(\mathrm{OH}) \mathrm{D}$ was observed. In Model 2, when adjusting for age, waist circumference, and LDL-c, $1.8 \%$ of the lnCRP variation could be explained $(p<0.00001)$. The inverse relationship between vitamin $\mathrm{D}$ status and CRP was slightly intensified when controlling for the covariates. Here, for each $1 \mathrm{nmol} / \mathrm{L}$ increase in $25(\mathrm{OH}) \mathrm{D}, \mathrm{CRP}$ decreased by $1.1 \%$. Excluding individuals with CRP concentrations above 
$10 \mathrm{mg} / \mathrm{L}$ - the clinical cut-off point for acute inflammation—resulted in similar trends being observed $(0.71 \%$ and $0.82 \%$ reduction per $1 \mathrm{nmol} / \mathrm{L}$ increase of $25(\mathrm{OH}) \mathrm{D}$ for unadjusted and adjusted models, respectively; results not shown).

\subsection{SNP Interaction}

All genotyped SNP frequencies reflected the assumptions of what would be expected under Hardy-Weinberg equilibrium. Previously, in our population, LD was reported between rs2027471 with rs1341665 and rs3093058 with rs3093062 [17]. In the subset of women studied here, the same LD pattern (Figure 2) was observed. Here, linkage was also detected for a haplogroup linking rs7553007, rs1341665, rs2027471, rs1205, and rs2794520 (Figure 2).

Physical Length:19.7kb

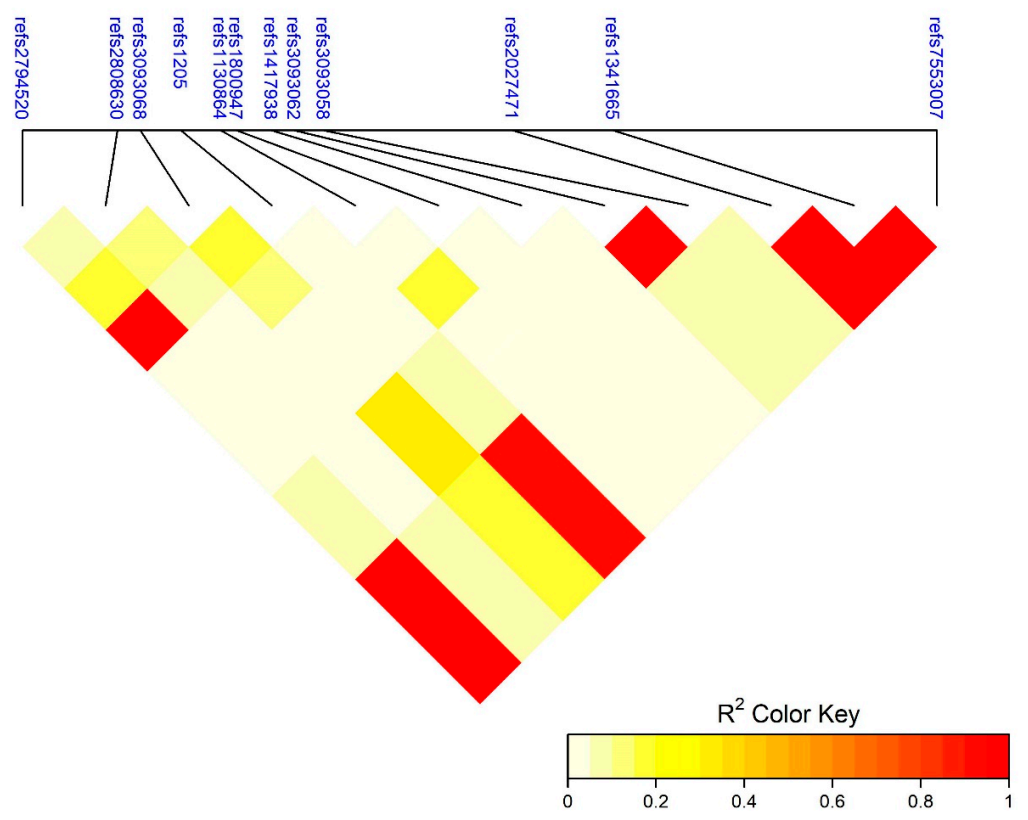

Figure 2. Linkage disequilibrium heatmap indicating linkage between 12 single nucleotide polymorphisms (SNPs) on the CRP gene.

Using the association analyses provided by the SNPassoc package in R, trends were investigated based on models of interaction between $25(\mathrm{OH}) \mathrm{D}$ concentrations with CRP SNPs on $\operatorname{lnCRP}$ concentrations. Associations were investigated under co-dominant, dominant, additive, and recessive genetic models, and the genetic model with the lowest AIC values was included (Supplementary Table S1). The minor alleles of the five SNPs (i.e., rs7553007, rs1341665, rs2027471, rs1205, and rs2794520) in high linkage were previously reported to be associated with decreases in circulating CRP [17], which was echoed by our results. Three SNPs were also significantly associated with increased CRP concentrations: rs3093058, rs3093062, and rs3093068.

To quantify whether $25(\mathrm{OH}) \mathrm{D}$ concentrations interacted with any of the 12 CRP SNPs to affect lnCRP concentrations, factorial analyses of co-variance with age, LDL-c, and waist circumference as covariates were performed. In the 12 SNPs investigated, $96.0 \%$ of the genetic variation could be grouped into six haplotypes. No interactions were observed between $25(\mathrm{OH}) \mathrm{D}$ concentrations and the identified haplotypes to affect $\operatorname{lnCRP}$ concentrations ( $p$ for trend $=0.68$ ). No significant associations between CRP SNPs and 25(OH)D were found under either the co-dominant or dominant model.

To investigate whether a genotype was associated with an increased risk of presenting with either deficient or insufficient 25(OH)D and elevated CRP concentrations, odds ratios (OR) were calculated 
using the SNPassoc library in R for each of the 12 SNPs while adjusting for age, LDL-c, and waist circumference (Table 3). The minor alleles of SNPs previously associated with significant increases in CRP concentrations were found to be at higher odds of co-presenting with insufficient/deficient $25(\mathrm{OH}) \mathrm{D}$ concentrations and vice versa. The minor alleles of the five SNPs in LD were associated with a reduced risk of presenting with the phenotype of inadequate $25(\mathrm{OH}) \mathrm{D}$ combined with elevated CRP concentrations (cases) compared to the phenotype presenting with either sufficient 25(OH)D or normal ( $<3 \mathrm{mg} / \mathrm{L})$ CRP concentrations. Of these, rs3093068, rs3093062, and rs3093058 presented with increased odds $(1.54,1.64$, and 1.67, respectively), while reduced odds were observed in rs2794520 and rs7553007 ( 0.65 and 0.67 , respectively) for individuals harboring the minor alleles. A trend towards significance for ORs for carriage of the minor alleles at two CRP SNPs (rs2027471 and rs1341665) to present with the co-phenotype was observed (OR: $0.05 ; p>0.05$ ).

Table 3. Genetic predisposition to develop insufficient/deficient $25(\mathrm{OH}) \mathrm{D}$ combined with elevated CRP concentrations adjusting for age, low-density lipoprotein cholesterol (LDL-c), and waist circumference.

\begin{tabular}{|c|c|c|c|c|c|c|c|}
\hline SNP ID & Allele & Control Phenotypes & $\%$ & Case Phenotypes & $\%$ & Odds Ratio (95\% CI) & $p$-Value \\
\hline \multirow{2}{*}{ rs2794520 } & $\mathrm{C} / \mathrm{C}$ & 166 & 57.4 & 141 & 66.8 & & \multirow{2}{*}{0.03} \\
\hline & $\mathrm{C} / \mathrm{T}-\mathrm{T} / \mathrm{T}$ & 123 & 42.6 & 70 & 33.2 & $0.65(0.44-0.95)$ & \\
\hline \multirow{2}{*}{ rs2808630 } & $\mathrm{T} / \mathrm{T}$ & 198 & 68.5 & 154 & 71.6 & & \multirow{2}{*}{ NS } \\
\hline & $\mathrm{C} / \mathrm{T}-\mathrm{C} / \mathrm{C}$ & 91 & 31.5 & 61 & 28.4 & $0.79(0.53-1.18)$ & \\
\hline \multirow{2}{*}{ rs3093068 } & $\mathrm{C} / \mathrm{C}$ & 123 & 42.9 & 72 & 33.5 & & \multirow{2}{*}{0.03} \\
\hline & $\mathrm{C} / \mathrm{G}-\mathrm{G} / \mathrm{G}$ & 164 & 57.1 & 143 & 66.5 & $1.54(1.05-2.26)$ & \\
\hline \multirow{2}{*}{ rs1205 } & $\mathrm{C} / \mathrm{C}$ & 171 & 59.2 & 142 & 66 & & \multirow{2}{*}{ NS } \\
\hline & $\mathrm{C} / \mathrm{T}-\mathrm{T} / \mathrm{T}$ & 118 & 40.8 & 73 & 34 & $0.72(0.49-1.05)$ & \\
\hline \multirow{2}{*}{ rs1130864 } & $\mathrm{C} / \mathrm{C}$ & 216 & 74.7 & 170 & 79.1 & & \multirow{2}{*}{ NS } \\
\hline & $\mathrm{C} / \mathrm{T}-\mathrm{T} / \mathrm{T}$ & 73 & 25.3 & 45 & 20.9 & $0.86(0.56-1.34)$ & \\
\hline \multirow{2}{*}{ rs1800947 } & $\mathrm{C} / \mathrm{C}$ & 289 & 100 & 213 & 99.1 & & \multirow{2}{*}{ NS } \\
\hline & $\mathrm{C} / \mathrm{G}$ & 0 & 0 & 2 & 0.9 & 0 & \\
\hline \multirow{2}{*}{ rs1417943 } & $\mathrm{A} / \mathrm{A}$ & 277 & 95.8 & 203 & 95.3 & & \multirow{2}{*}{ NS } \\
\hline & $\mathrm{A} / \mathrm{T}$ & 12 & 4.2 & 10 & 4.7 & $1.7(0.70-4.13)$ & \\
\hline \multirow{2}{*}{ rs3093062 } & $\mathrm{G} / \mathrm{G}$ & 214 & 74.3 & 137 & 63.7 & & \multirow{2}{*}{0.02} \\
\hline & $\mathrm{A} / \mathrm{G}-\mathrm{A} / \mathrm{A}$ & 74 & 25.7 & 78 & 36.3 & $1.64(1.10-2.45)$ & \\
\hline \multirow{2}{*}{ rs3093058 } & $\mathrm{A} / \mathrm{A}$ & 215 & 74.4 & 135 & 63.4 & & \multirow{2}{*}{0.01} \\
\hline & $\mathrm{A} / \mathrm{T}-\mathrm{T} / \mathrm{T}$ & 74 & 25.6 & 78 & 36.6 & $1.67(1.12-2.50)$ & \\
\hline \multirow{2}{*}{ rs2027471 } & $\mathrm{T} / \mathrm{T}$ & 167 & 57.8 & 142 & 66 & & \multirow{2}{*}{0.05} \\
\hline & $\mathrm{A} / \mathrm{T}-\mathrm{A} / \mathrm{A}$ & 122 & 42.2 & 73 & 34 & $0.68(0.46-1.00)$ & \\
\hline \multirow{2}{*}{ rs1341665 } & $\mathrm{G} / \mathrm{G}$ & 167 & 57.8 & 142 & 66 & & \multirow{2}{*}{0.05} \\
\hline & $\mathrm{A} / \mathrm{G}-\mathrm{A} / \mathrm{A}$ & 122 & 42.2 & 73 & 34 & $0.68(0.46-1.00)$ & \\
\hline \multirow{2}{*}{ rs7553007 } & G/G & 164 & 56.7 & 141 & 65.6 & & \multirow{2}{*}{0.04} \\
\hline & $\mathrm{A} / \mathrm{G}-\mathrm{A} / \mathrm{A}$ & 125 & 43.3 & 74 & 34.4 & $0.67(0.46-0.98)$ & \\
\hline
\end{tabular}

Cases are those presenting with the phenotype of deficient or insufficient 25(OH)D together with elevated (>3 mg/L) CRP concentrations. Controls were individuals with normal CRP and/or sufficient 25(OH)D concentrations. The reference group comprised those homozygotes for the wild-type allele. Abbreviations: $25(\mathrm{OH}) \mathrm{D}$, 25-hydroxyvitamin D; A, adenine; C, cytosine; CI, confidence interval; G, guanine; rs, reference SNP cluster ID; $\mathrm{T}$, thymine.

\section{Discussion}

In this research, we confirmed the existence of an inverse relationship between CRP and vitamin $\mathrm{D}$ and attempted to unravel the mechanisms involved. From this study, we know that vitamin D status does not directly modulate CRP via CRP SNPs nor do CRP SNPs influence vitamin D, even though these SNPs influence CRP concentrations (data presented elsewhere). Since we found that the double phenotype of high CRP and low vitamin D was associated with particular CRP SNPs, we hypothesized that negative feedback mechanisms were at play (will be described later). In cases where these genotypes were co-observed with low 25(OH)D concentrations, poorer CVD markers were also observed, such as elevated blood pressure.

The majority $(65.5 \%)$ of the South African women in our cohort had 25(OH)D concentrations lower than the recommended $75 \mathrm{nmol} / \mathrm{L}$. Moreover, $42.8 \%$ of them presented with the co-burden of low vitamin D status combined with elevated CRP concentrations. Having deficient or insufficient $25(\mathrm{OH}) \mathrm{D}$ and elevated CRP concentrations was previously shown to increase the risk of developing 
various chronic non-communicable conditions, such as CVD [5,31,34]. In our study, volunteers classified as cases (those presenting with both low vitamin D status and high CRP concentrations) had significantly higher blood pressure and anthropometrical markers (even when adjusting for waist circumference), precursors in the etiology of CVD, than controls. We established that vitamin $\mathrm{D}$ correlated inversely with CRP, which is in accordance with a previous report [13]. Moreover, we found that CRP decreased within increasing strata of $25(\mathrm{OH}) \mathrm{D}$ categories as recommended by the Endocrine Society [47] and confirmed this inverse association with our regression models. Furthermore, we proposed that $25(\mathrm{OH}) \mathrm{D}$ might interact with SNPs located on the CRP gene, thereby influencing CRP concentrations. Contrary to our hypothesis, none of the CRP SNPs investigated showed any interactions with circulating $25(\mathrm{OH}) \mathrm{D}$; thus, vitamin $\mathrm{D}$ does not modulate $C R P$ genotypes to influence CRP concentrations. The inverse association between vitamin D and CRP is therefore not due to nutrigenetic effects. A recent Mendelian association study also found a lack of association between 25(OH)D and genetic markers influencing CRP concentrations [13] even though they detected a negative correlation between $25(\mathrm{OH}) \mathrm{D}$ and CRP concentrations.

We also investigated whether CRP SNPs influenced 25(OH)D concentrations directly to learn whether a possible unknown backward feedback mechanism might exist or whether certain CRP SNPs predispose individuals to having heightened inflammation, with concurring maladies, leading to reduced UV exposure resulting in altered vitamin D status, but found no associations. We then determined whether harboring CRP genotypes could increase the odds of co-presenting with both high CRP and low vitamin D status. Carriage of the minor allele at three SNPs (rs3093068, rs3093058, and rs3093062) was associated with increased odds, while harboring the variant allele at two SNPs (rs2794520 and rs7553007) resulted in lower odds to present with the phenotype of insufficient/deficient $25(\mathrm{OH}) \mathrm{D}(<75 \mathrm{nmol} / \mathrm{L})$ and elevated CRP concentrations ( $>3 \mathrm{mg} / \mathrm{L}$ ). This is, to our knowledge, a novel addition to the existing literature, as these genetic effectors were not previously reported in this context.

How blood pressure is influenced by vitamin D status remains inconclusive [48], although there are suggestions of causative pathways [49]. Li [50] hypothesized that vitamin D could have an influence on the renin-angiotensin system (RAS), which was substantiated by a study that reported how low concentrations of $25(\mathrm{OH}) \mathrm{D}$ upregulated the RAS [51]. In our population, $25(\mathrm{OH}) \mathrm{D}$ was reported to be associated with carotid wall thickening and arterial stiffness [52], both being attributes observed in individuals with increased CRP concentrations. This is a possible mechanism whereby low $25(\mathrm{OH}) \mathrm{D}$ could result in increased arterial stiffness, and in turn result in increased blood pressure [53], leading to elevated CRP concentration by negative feedback mechanisms. Individuals with the case phenotype were also investigated in another population, where cases had worse pro-inflammatory marker panels than controls [54]. However, with increasing CRP concentrations, it was reported that the anti-inflammatory effects of vitamin D decreased substantially and most of the other pro-inflammatory markers were upregulated [54]. These risk factors are further exacerbated by the presence of abdominal adiposity observed in our population [55], thereby further increasing the risk of developing CVD by means of increased pro-inflammatory factors (such as IL-6) released by adipose tissue. Another possibility is that low vitamin D status has harmful side effects that are pro-inflammatory themselves; alternatively, synergistic effects between these two factors may exist, explaining the co-existence of low vitamin $\mathrm{D}$ with high CRP, as was the case in Kuwaiti women [54]. Low concentrations of 25(OH)D have been linked to an increased risk of developing CVD [56], although definite conclusions remain ambiguous [57]. Similarly, CRP has been strongly associated with increased CVD risk [6]. Future studies should explore possible mechanisms for the inverse association between $25(\mathrm{OH}) \mathrm{D}$ and CRP further, as well as whether the presence of both low vitamin D status and inflammation might heighten disease risk.

Differences in 25(OH)D were observed among individuals residing in the two different locations (A and B) that were investigated here (Supplementary Table S2). Although 25(OH)D and CRP values were closer to the recommended concentrations in rural participants, neither median 25(OH)D nor CRP concentrations met the recommended guidelines in both population subdivisions. Rural-urban differences in 25(OH)D disappeared when adjustments for age were made. Although age was 
reported as a non-significant contributor to our linear models, it was included in analyses as a possible covariate based on four previously reported reasons. First, aging results in decreased concentrations of 7-dehydrocholesterol in the epidermis, which in turn reduces the response to UV light and subsequently results in decreased formation of pre-vitamin $\mathrm{D}_{3}[58,59]$. Second, a decline in absorption, transport, or liver hydroxylation of orally ingested vitamin D sources was reported in older individuals [60]. Increased frailty with advancing age may also result in individuals spending less time outdoors, affecting their exposure to UV sources. Lastly, age, sex, and ethnicity are recommended factors to adjust for when conducting predictive analyses for CRP [12], with sex and ethnicity controlled for in our black, female population. It could, however, be argued that environmental and climate differences, such as reduced UVR, could have affected $25(\mathrm{OH}) \mathrm{D}$ concentrations between individuals located in the two different locations of our study. These places, A and B, whence we drew our samples, were on similar latitudes; when measured using the equator as a reference the difference between them was $14 \mathrm{~km}$. In terms of elevation above sea level, they differed by less than $80 \mathrm{~m}$. The likely differences in UV radiation were therefore small. Data pertaining to environmental factors influencing vitamin D synthesis in individuals were not available from ground observations in these localities and, therefore, satellite observations were used. Similar mean average temperatures near the earth's surface, UV indices, erythemal dose rates, and total ozone columns were observed between the two areas from which we recruited volunteers. Another factor that could have affected 25(OH)D concentrations in rural participants is differences in lifestyle, as observed in Asian [61], other African [62], and European [63] populations. As no data were available pertaining to sun exposure in our study, no inference about differences in lifestyle was possible. Low 25(OH)D concentrations have also been linked to an increased risk of obesity [31]; however, for the population investigated similar anthropometric markers were observed across differing $25(\mathrm{OH}) \mathrm{D}$ status. The lack of association between BMI and $25(\mathrm{OH}) \mathrm{D}$ concentrations was reported in another South African study, where recruitment was done in a province that neighbors the one from which we selected our volunteers [64]. This may indicate that the correlation between anthropometric markers and 25(OH)D status does not apply to black individuals living in South Africa, which necessitates further investigation.

Nutritional intake of vitamin $\mathrm{D}$ in our population did not differ between the three 25(OH)D categories and was well below the recommended $15 \mu \mathrm{g} /$ day [27]. Dietary vitamin D also failed to influence the linear regression modeling of $\operatorname{lnCRP}$ concentrations, which might be due to the extremely low dietary intake observed. A low intake of dietary vitamin D is common in African populations, with only margarine being fortified with vitamin D in South Africa [27]. Dietary sources of vitamin D did not significantly contribute to vitamin D status [65], as ingested vitamin D is more readily excreted [66]. This result aligns with the fact that the primary factor contributing to $25(\mathrm{OH}) \mathrm{D}$ concentration is exposure to UV light [24], resulting in vitamin $\mathrm{D}_{3}$ (cholecalciferol or calcidiol) synthesis from 7-dehydrocholesterol (a precursor of cholesterol); after hydroxylation by the liver and kidneys, vitamin $\mathrm{D}_{3}$ becomes $25(\mathrm{OH}) \mathrm{D}$ and then 1,25-dihydroxyvitamin D. That said, a study controlling caloric intake of obese women showed that replenishment of 25(OH)D by supplementation with vitamin D at $2000 \mathrm{IU}$ per day led to participants in that group losing more weight, having smaller waist circumferences, and a $46 \%$ higher reduction in CRP concentrations compared to those in a placebo group [67]. Because a placebo group was included in this other study, the reduction in CRP was attributed to $25(\mathrm{OH}) \mathrm{D}$ values stabilizing at sufficient levels [67], not simply a reduction of body composition markers. We attributed the elevated CRP concentrations observed in our urban population to increased abdominal adiposity, as urban individuals had increased waist circumferences. In their review, Brooks et al. [68] reported that the association between inflammation, as measured by CRP, and abdominal adiposity is highly correlated, even when correcting for BMI. Women with increased waist circumferences were previously reported to be at greater risk of co-presenting with elevated CRP concentrations [69], with our results indicating that waist circumference was also the largest effector contributing to CRP concentrations. Reductions in abdominal adiposity in response to dietary interventions were previously reported to reduce CRP concentrations [70]. These dietary interventions included supplementation with fish oil tablets, and although not stated in the original work, 
fish oil naturally contains bioavailable vitamin $\mathrm{D}$, which could have contributed to the reduction in CRP concentrations [71]. Here, we report a predicted $0.15 \mathrm{mg} / \mathrm{L}$ reduction in CRP concentration with a 1 $\mathrm{nmol} / \mathrm{L}$ increase in $25(\mathrm{OH}) \mathrm{D}$ concentrations as determined from Spearman correlation. Recommendations intended to achieve sufficient $25(\mathrm{OH}) \mathrm{D}$ status should, therefore, aim to include responsible guidelines for exposure to sunlight, as well as an increase in the intake of good dietary sources of vitamin $D$ to improve health in a country such as South Africa, which has a history of health policies failing its citizens.

At the time of our study, South Africa was rife with HIV denialism by government and stigmatization of seropositive individuals, which resulted in a large segment of the population not knowing their HIV status. Overall, $8.1 \%$ of our study population was first diagnosed as being HIV-positive during our investigation. Median values, when excluding HIV-positive individuals, were similar, in terms of both $25(\mathrm{OH}) \mathrm{D}$ and CRP concentrations, to those of the whole group. Both 25(OH)D [72] and CRP [73] concentrations can be affected by the use of anti-retroviral (ARV) treatments; however, as these individuals were first diagnosed during this study, they were not receiving ARVs and were therefore not excluded.

Our study was not without limitations. Because gender is a factor that contributes to both $25(\mathrm{OH}) \mathrm{D}$ and CRP concentrations, including men in our sample would have made the study more informative. Future studies should aim to explore the relationship between vitamin D and inflammation in men as well as women. Furthermore, no data were available on sun exposure time, which could have contributed to explaining the variance in $25(\mathrm{OH}) \mathrm{D}$ concentrations. However, measuring $25(\mathrm{OH}) \mathrm{D}$ concentrations is a strength of our study as it avoids the necessity for UVR, sun exposure time, and even dietary vitamin $\mathrm{D}$ intake data. The cohort was also randomly selected, without prior genetic screening. Future studies, including more extensive numbers of minor allele carriers, could establish associations between SNPs where our population had too few genotypes, resulting in lowered statistical power. Because 1,25(OH)2D is epigenetically active [74], future investigations to explore a possible mechanism to explain the anti-inflammatory effects of vitamin D could also incorporate epigenetics.

Our study cohort was very well-described, with data available on daily vitamin D intake, and was particularly well-characterized in terms of demographic, genetic, and biochemical factors that could address the variance in circulating CRP concentrations. The unique population investigated here was ideal, as individuals presented with both low 25(OH)D and elevated CRP concentrations. Including both CRP concentrations, known to fluctuate quite extensively, and genetic constants with known effects on CRP phenotype further strengthens the data presented here.

\section{Conclusions}

Disturbingly, $43 \%$ of our female cohort presented with both elevated CRP concentrations and deficient/insufficient 25(OH)D levels; because the combination is linked to CVD, this may compound their disease risk and predispose them to future disease. A negative association was identified between 25(OH)D and circulating CRP concentrations, but no vitamin D-gene interactions were observed between common SNPs on the CRP gene and 25(OH)D in this study. Moreover, CRP SNPs did not influence vitamin $\mathrm{D}$ status. Several genotypes were, however, associated with an altered risk of presenting with the co-phenotype of insufficient/deficient $25(\mathrm{OH}) \mathrm{D}$ and elevated CRP, indicating that a genetic predisposition exists. The present research extends past work by demonstrating that the link between 25(OH)D and CRP is not associated with vitamin D-CRP gene interactions and that other pathways need to be investigated. This finding is important, as it offers a starting point for unraveling the possible mechanisms for the previously reported inverse relationship between $25(\mathrm{OH}) \mathrm{D}$ and CRP, which in turn may ultimately result in therapeutic and policy recommendations to combat CVD.

This paper highlights the necessity of public health efforts in South Africa to assist women to achieve sufficient vitamin D status through responsible exposure to sunlight, increased intake of natural and fortified dietary sources of vitamin $\mathrm{D}$, and for those who require it, vitamin $\mathrm{D}$ supplementation. Improved vitamin D status would reduce inflammation and thus possibly curb diseases contingent on both low vitamin D and elevated CRP: the co-phenotype described here. 
Supplementary Materials: The following are available online at www.mdpi.com/1660-4601/15/1/111/s1. Table S1. Environment-SNP associations with CRP concentrations based on different genetic models of inheritance. Table S2. Demographic markers associated with differing $25(\mathrm{OH}) \mathrm{D}$ status.

Acknowledgments: PURE Africa: Annamarie Kruger (posthumous), Minrie Greeff, Poncho G. Molaudzi, Vasti Kruger, Juanita Brits, and Paula Jardim working in the Africa Unit for Transdisciplinary Health Research (AUTHeR), Faculty of Health Sciences, North-West University, Potchefstroom, South Africa, as well as all the field workers over the years. PURE International: Salim Yusuf and the PURE project office staff at the Population Health Research Institute (PHRI), Hamilton Health Sciences, and McMaster University, Ontario, Canada. Funders: SANPAD (South Africa-The Netherlands Research Program on Alternatives in Development (08/15)), South African National Research Foundation (NRF GUN No. 2069139 and FA2006040700010), South African Medical Research Council, North-West University, Potchefstroom, South Africa, and the Population Health Research Institute, Ontario, Canada. Analyses and visualizations used in this paper were produced with the Giovanni online data system, developed and maintained by the NASA GES DISC.

Author Contributions: Pieter H. Myburgh concept, statistical analyses, and writing and critical review of manuscript; Cornelie Nienaber-Rousseau refining concept of study, isolated DNA, and writing and critical review of manuscript; Iolanthé M. Kruger PI of PURE SA-NW, funding and management of anthropometrical, nutritional, and biochemical measures, and critical review of manuscript; G. Wayne Towers refining concept, funding and management of genetic analyses, and critical review and writing of manuscript.

Conflicts of Interest: The authors declare no conflict of interest.

\section{References}

1. Nyirenda, M.J. Non-communicable diseases in sub-Saharan Africa: Understanding the drivers of the epidemic to inform intervention strategies. Int. Health 2016, 8, 157-158. [CrossRef] [PubMed]

2. Sliwa, K.; Wilkinson, D.; Hansen, C.; Ntyintyane, L.; Tibazarwa, K.; Becker, A.; Stewart, S. Spectrum of heart disease and risk factors in a black urban population in South Africa (the Heart of Soweto Study): A cohort study. Lancet 2008, 371, 915-922. [CrossRef]

3. Statistics South Africa. Mortality and Causes of Death in South Africa, 2015: Findings from Death Notification; Statistics South Africa: Pretoria, Gauteng, 2017; p. 140.

4. Ruiz-Núñez, B.; Pruimboom, L.; Dijck-Brouwer, D.A.J.; Muskiet, F.A.J. Lifestyle and nutritional imbalances associated with Western diseases: Causes and consequences of chronic systemic low-grade inflammation in an evolutionary context. J. Nutr. Biochem. 2013, 24, 1183-1201. [CrossRef] [PubMed]

5. Shrivastava, A.K.; Singh, H.V.; Raizada, A.; Singh, S.K. C-reactive protein, inflammation and coronary heart disease. Egypt. Heart J. 2015, 67, 89-97. [CrossRef]

6. Ridker, P.M. From C-reactive protein to interleukin-6 to interleukin-1. Circ. Res. 2016, 118, 145-156. [CrossRef] [PubMed]

7. Strang, F.; Schunkert, H. C-reactive protein and coronary heart disease: All said, is not it? Mediat. Inflamm. 2014, 2014, 757123. [CrossRef] [PubMed]

8. King, K. Neighborhood walkable urban form and C-reactive protein. Prev. Med. 2013, 57, 850-854. [CrossRef] [PubMed]

9. Albert, M.A.; Glynn, R.J.; Ridker, P.M. Alcohol consumption and plasma concentration of C-reactive protein. Circulation 2003, 107, 443-447. [CrossRef] [PubMed]

10. Deverts, D.J.; Cohen, S.; Kalra, P.; Matthews, K.A. The prospective association of socioeconomic status with C-reactive protein levels in the CARDIA study. Brain Behav. Immun. 2012, 26, 1128-1135. [CrossRef] [PubMed]

11. Shen, J.; Ordovas, J.M. Impact of genetics and environmental factors on CRP levels and response to therapeutic agents. Clin. Chem. 2009, 55, 256-264. [CrossRef] [PubMed]

12. Wener, M.H.; Daum, P.R.; McQuillan, G.M. The influence of age, sex, and race on the upper reference limit of serum C-reactive protein concentration. J. Rheumatol. 2000, 27, 2351-2359. [PubMed]

13. Liefaard, M.C.; Ligthart, S.; Vitezova, A.; Hofman, A.; Uitterlinden, A.G.; Kiefte-de Jong, J.C.; Franco, O.H.; Zillikens, M.C.; Dehghan, A. Vitamin D and C-reactive protein: A Mendelian randomization study. PLoS ONE 2015, 10, e0131740. [CrossRef] [PubMed]

14. Carlson, N.; Mah, R.; Aburto, M.; Peters, M.J.; Dupper, M.V.; Chen, L.H. Hypovitaminosis D correction and high-sensitivity C-reactive protein levels in hypertensive adults. Perm. J. 2013, 17, 19-21. [CrossRef] [PubMed]

15. Chen, N.; Wan, Z.; Han, S.F.; Li, B.Y.; Zhang, Z.L.; Qin, L.Q. Effect of vitamin D supplementation on the level of circulating high-sensitivity C-reactive protein: A meta-analysis of randomized controlled trials. Nutrients 2014, 6, 2206-2216. [CrossRef] [PubMed] 
16. Pankow, J.S.; Folsom, A.R.; Cushman, M.; Borecki, I.B.; Hopkins, P.N.; Eckfeldt, J.H.; Tracy, R.P. Familial and genetic determinants of systemic markers of inflammation: The NHLBI family heart study. Atherosclerosis 2001, 154, 681-689. [CrossRef]

17. Nienaber-Rousseau, C.; Swanepoel, B.; Dolman, R.C.; Pieters, M.; Conradie, K.R.; Towers, G.W. Interactions between $\mathrm{C}$-reactive protein genotypes with markers of nutritional status in relation to inflammation. Nutrients 2014, 6, 5034-5050. [CrossRef] [PubMed]

18. Bipath, P.; Viljoen, M.; Levay, P.F. Levels of procalcitonin, C-reactive protein and neopterin in patients with advanced HIV-1 infection. S. Afr. J. HIV Med. 2012, 13, 78-82. [CrossRef]

19. Nazmi, A.; Victora, C.G. Socioeconomic and racial/ethnic differentials of C-reactive protein levels: A systematic review of population-based studies. BMC Public Health 2007, 7, 212. [CrossRef] [PubMed]

20. Shah, T.; Newcombe, P.; Smeeth, L.; Addo, J.; Casas, J.P.; Whittaker, J.; Miller, M.A.; Tinworth, L.; Jeffery, S.; Strazzullo, P.; et al. Ancestry as a determinant of mean population C-reactive protein values: Implications for cardiovascular risk prediction. Circ. Cardiovasc. Genet. 2010, 3, 436-444. [CrossRef] [PubMed]

21. Mokhaneli, M.C.; Fourie, C.M.; Botha, S.; Mels, C.M. The association of oxidative stress with arterial compliance and vascular resistance in a bi-ethnic population: The SABPA study. Free Radic. Res. 2016, 50, 920-928. [CrossRef] [PubMed]

22. Fitzpatrick, T.B. The validity and practicality of sun-reactive skin types I through VI. Arch. Dermatol. 1988, 124, 869-871. [CrossRef] [PubMed]

23. Jablonski, N.G.; Chaplin, G. Human skin pigmentation as an adaptation to UV radiation. Proc. Natl. Acad. Sci. USA 2010, 107, 8962-8968. [CrossRef] [PubMed]

24. Harris, S.S. Vitamin D and African Americans. J. Nutr. 2006, 136, 1126-1129. [PubMed]

25. Wright, C.Y.; Norval, M.; Summers, B.; Davids, L.M.; Coetzee, G.; Oriowo, M. Solar ultraviolet radiation exposure and human health in South Africa: Finding a balance. S. Afr. Med. J. 2012, 102, 665-666. [CrossRef] [PubMed]

26. O'Connor, M.Y.; Thoreson, C.K.; Ramsey, N.L.M.; Ricks, M.; Sumner, A.E. The Uncertain Significance of Low Vitamin D levels in African Descent Populations: A Review of the Bone and Cardiometabolic Literature. Prog. Cardiovasc. Dis. 2013, 56, 261-269. [CrossRef] [PubMed]

27. Norval, M.; Coussens, A.K.; Wilkinson, R.J.; Bornman, L.; Lucas, R.M.; Wright, C.Y. Vitamin D Status and Its Consequences for Health in South Africa. Int. J. Environ. Res. Public Health 2016, 13, 1019. [CrossRef] [PubMed]

28. Tsiaras, W.G.; Weinstock, M.A. Factors Influencing Vitamin D Status. Acta Derm.-Venereol. 2011, 91, 115-124. [CrossRef] [PubMed]

29. Je, L.; Js, A. Vitamin D in HIV-infected patients. Curr. HIV/AIDS Rep. 2011, 8, 133-141.

30. Kassi, E.N.; Stavropoulos, S.; Kokkoris, P.; Galanos, A.; Moutsatsou, P.; Dimas, C.; Papatheodorou, A.; Zafeiris, C.; Lyritis, G. Smoking is a significant determinant of low serum vitamin D in young and middle-aged healthy males. Hormones 2015, 14, 245-250. [CrossRef] [PubMed]

31. Rosen, C.J.; Adams, J.S.; Bikle, D.D.; Black, D.M.; Demay, M.B.; Manson, J.E.; Murad, M.H.; Kovacs, C.S. The nonskeletal effects of vitamin D: An Endocrine Society scientific statement. Endocr. Rev. 2012, 33, 456-492. [CrossRef] [PubMed]

32. Brondum-Jacobsen, P.; Benn, M.; Jensen, G.B.; Nordestgaard, B.G. 25-hydroxyvitamin d levels and risk of ischemic heart disease, myocardial infarction, and early death: Population-based study and meta-analyses of 18 and 17 studies. Arterioscler. Thromb. Vasc. Biol. 2012, 32, 2794-2802. [CrossRef] [PubMed]

33. Brondum-Jacobsen, P.; Nordestgaard, B.G.; Schnohr, P.; Benn, M. 25-hydroxyvitamin D and symptomatic ischemic stroke: An original study and meta-analysis. Ann. Neurol. 2013, 73, 38-47. [CrossRef] [PubMed]

34. Chowdhury, R.; Kunutsor, S.; Vitezova, A.; Oliver-Williams, C.; Chowdhury, S.; Kiefte-de-Jong, J.C.; Khan, H.; Baena, C.P.; Prabhakaran, D.; Hoshen, M.B.; et al. Vitamin D and risk of cause specific death: Systematic review and meta-analysis of observational cohort and randomised intervention studies. BMJ 2014, 348, g1903. [CrossRef] [PubMed]

35. Dickie, L.J.; Church, L.D.; Coulthard, L.R.; Mathews, R.J.; Emery, P.; McDermott, M.F. Vitamin D3 down-regulates intracellular Toll-like receptor 9 expression and Toll-like receptor 9-induced IL-6 production in human monocytes. Rheumatology 2010, 49, 1466-1471. [CrossRef] [PubMed]

36. Zhang, D.; Sun, M.; Samols, D.; Kushner, I. STAT3 participates in transcriptional activation of the C-reactive protein gene by interleukin-6. J. Biol. Chem. 1996, 271, 9503-9509. [CrossRef] [PubMed] 
37. Bode, J.G.; Albrecht, U.; Haussinger, D.; Heinrich, P.C.; Schaper, F. Hepatic acute phase proteins-Regulation by IL-6- and IL-1-type cytokines involving STAT3 and its crosstalk with NF-kB-dependent signaling. Eur. J. Cell Biol. 2012, 91, 496-505. [CrossRef] [PubMed]

38. Carlson, R.V.; Boyd, K.M.; Webb, D.J. The revision of the Declaration of Helsinki: Past, present and future. Br. J. Clin. Pharmacol. 2004, 57, 695-713. [CrossRef] [PubMed]

39. Teo, K.; Chow, C.K.; Vaz, M.; Rangarajan, S.; Yusuf, S. The Prospective Urban Rural Epidemiology (PURE) study: Examining the impact of societal influences on chronic noncommunicable diseases in low-, middle-, and high-income countries. Am. Heart J. 2009, 158, 1-7. [CrossRef] [PubMed]

40. Vorster, H.H.; Kruger, A.; Wentzel-Viljoen, E.; Kruger, H.S.; Margetts, B.M. Added sugar intake in South Africa: Findings from the Adult Prospective Urban and Rural Epidemiology cohort study. Am. J. Clin. Nutr. 2014, 99, 1479-1486. [CrossRef] [PubMed]

41. Friedewald, W.T.; Levy, R.I.; Fredrickson, D.S. Estimation of the concentration of low-density lipoprotein cholesterol in plasma, without use of the preparative ultracentrifuge. Clin. Chem. 1972, 18, 499-502. [PubMed]

42. MacIntyre, U.E.; Venter, C.S.; Vorster, H.H.; Steyn, H.S. A combination of statistical methods for the analysis of the relative validation data of the quantitative food frequency questionnaire used in the THUSA study. Transition, Health and Urbanisation in South Africa. Public Health Nutr. 2001, 4, 45-51. [CrossRef] [PubMed]

43. Acker, J.G.; Leptoukh, G. Online analysis enhances use of NASA Earth science data. Eos Trans. Am. Geophys. Union 2007, 88, 14-17. [CrossRef]

44. R Core Team. R: A Language and Environment for Statistical Computing; R Foundation for Statistical Computing: Vienna, Austria, 2017.

45. Subirana, I.; Sanz, H.; Vila, J. Building bivariate tables: The compareGroups package for R. J. Stat. Softw. 2014, 57, 1-16. [CrossRef]

46. Gonzalez, J.R.; Armengol, L.; Sole, X.; Guino, E.; Mercader, J.M.; Estivill, X.; Moreno, V. SNPassoc: An R package to perform whole genome association studies. Bioinformatics 2007, 23, 644-645. [CrossRef] [PubMed]

47. Holick, M.F.; Binkley, N.C.; Bischoff-Ferrari, H.A.; Gordon, C.M.; Hanley, D.A.; Heaney, R.P.; Murad, M.H.; Weaver, C.M. Evaluation, treatment, and prevention of vitamin D deficiency: An Endocrine Society clinical practice guideline. J. Clin. Endocrinol. Metab. 2011, 96, 1911-1930. [CrossRef] [PubMed]

48. Tamez, H.; Kalim, S.; Thadhani, R.I. Does vitamin D modulate blood pressure? Curr. Opin. Nephrol. Hypertens. 2013, 22, 204-209. [CrossRef] [PubMed]

49. Sluyter, J.D.; Camargo, C.A., Jr.; Stewart, A.W.; Waayer, D.; Lawes, C.M.M.; Toop, L.; Khaw, K.T.; Thom, S.A.M.; Hametner, B.; Wassertheurer, S.; et al. Effect of Monthly, High-Dose, Long-Term Vitamin D Supplementation on Central Blood Pressure Parameters: A Randomized Controlled Trial Substudy. J. Am. Heart Assoc. 2017, 6, e006802. [CrossRef] [PubMed]

50. Li, Y.C. Vitamin D regulation of the renin-angiotensin system. J. Cell. Biochem. 2003, 88, 327-331. [CrossRef] [PubMed]

51. Tomaschitz, A.; Pilz, S.; Ritz, E.; Grammer, T.; Drechsler, C.; Boehm, B.O.; Marz, W. Independent association between 1,25-dihydroxyvitamin D, 25-hydroxyvitamin D and the renin-angiotensin system: The Ludwigshafen Risk and Cardiovascular Health (LURIC) study. Clin. Chim. Acta Int. J. Clin. Chem. 2010, 411, 1354-1360. [CrossRef] [PubMed]

52. Gafane, L.F.; Schutte, R.; Kruger, I.M.; Schutte, A.E. Large artery stiffness and carotid intima-media thickness in relation to markers of calcium and bone mineral metabolism in African women older than 46 years. J. Hum. Hypertens. 2015, 29, 152-158. [CrossRef] [PubMed]

53. Kruger, I.M.; Kruger, M.C.; Doak, C.M.; Schutte, A.E.; Huisman, H.W.; Van Rooyen, J.M.; Schutte, R.; Malan, L.; Malan, N.T.; Fourie, C.M.T.; et al. The association of $25(\mathrm{OH}) \mathrm{D}$ with blood pressure, pulse pressure and carotid-radial pulse wave velocity in African women. PLoS ONE 2013, 8, e54554. [CrossRef] [PubMed]

54. Azizieh, F.; Alyahya, K.O.; Raghupathy, R. Association between levels of vitamin D and inflammatory markers in healthy women. J. Inflamm. Res. 2016, 9, 51-57. [CrossRef] [PubMed]

55. Nienaber-Rousseau, C.; Sotunde, O.; Ukegbu, P.; Myburgh, P.; Wright, H.; Havemann-Nel, L.; Moss, S.; Kruger, I.; Kruger, H. Socio-demographic and lifestyle factors predict 5-year changes in adiposity among a group of black South African adults. Int. J. Environ. Res. Public Health 2017, 14, 1089. [CrossRef] [PubMed]

56. Muscogiuri, G.; Annweiler, C.; Duval, G.; Karras, S.; Tirabassi, G.; Salvio, G.; Balercia, G.; Kimball, S.; Kotsa, K.; Mascitelli, L.; et al. Vitamin D and cardiovascular disease: From atherosclerosis to myocardial infarction and stroke. Int. J. Cardiol. 2017, 230, 577-584. [CrossRef] [PubMed] 
57. Al Mheid, I.; Quyyumi, A.A. Vitamin D and cardiovascular disease. J. Am. Coll. Cardiol. 2017, 70, 89-100. [CrossRef] [PubMed]

58. MacLaughlin, J.; Holick, M.F. Aging decreases the capacity of human skin to produce vitamin D3. J. Clin. Investig. 1985, 76, 1536-1538. [CrossRef] [PubMed]

59. Gallagher, J.C. Vitamin D and aging. Endocrinol. Metab. Clin. N. Am. 2013, 42, 319-332. [CrossRef] [PubMed]

60. Harris, S.S.; Dawson-Hughes, B.; Perrone, G.A. Plasma 25-hydroxyvitamin D responses of younger and older men to three weeks of supplementation with $1800 \mathrm{IU} /$ day of vitamin D. J. Am. Coll. Nutr. 1999, 18, 470-474. [CrossRef] [PubMed]

61. Anwar, S.; Iqbal, M.P.; Azam, I.; Habib, A.; Bhutta, S.; Soofi, S.B.; Bhutta, Z.A. Urban and rural comparison of vitamin D status in Pakistani pregnant women and neonates. J. Obstet. Gynaecol. 2016, 36, 318-323. [CrossRef] [PubMed]

62. Wakayo, T.; Belachew, T.; Vatanparast, H.; Whiting, S.J. Vitamin D deficiency and its predictors in a country with thirteen months of sunshine: The case of school children in central Ethiopia. PLoS ONE 2015, 10, e0120963. [CrossRef] [PubMed]

63. Manicourt, D.H.; Devogelaer, J.P. Urban tropospheric ozone increases the prevalence of vitamin D deficiency among Belgian postmenopausal women with outdoor activities during summer. J. Clin. Endocrinol. Metab. 2008, 93, 3893-3899. [CrossRef] [PubMed]

64. Lategan, R.; van den Berg, V.L.; Ilich, J.Z.; Walsh, C.M. Vitamin D status, hypertension and body mass index in an urban black community in Mangaung, South Africa. Afr. J. Prim. Health Care Fam. Med. 2016, 8, 1210. [CrossRef] [PubMed]

65. Holick, M.F.; Chen, T.C. Vitamin D deficiency: A worldwide problem with health consequences. Am. J. Clin. Nutr. 2008, 87, 1080s-1086s. [CrossRef] [PubMed]

66. Haddad, J.G.; Matsuoka, L.Y.; Hollis, B.W.; Hu, Y.Z.; Wortsman, J. Human plasma transport of vitamin D after its endogenous synthesis. J. Clin. Investig. 1993, 91, 2552-2555. [CrossRef] [PubMed]

67. Mason, C.; Xiao, L.; Imayama, I.; Duggan, C.; Wang, C.-Y.; Korde, L.; McTiernan, A. Vitamin D(3) supplementation during weight loss: A double-blind randomized controlled trial. Am. J. Clin. Nutr. 2014, 99, 1015-1025. [CrossRef] [PubMed]

68. Brooks, G.C.; Blaha, M.J.; Blumenthal, R.S. Relation of C-reactive protein to abdominal adiposity. Am. J. Cardiol. 2010, 106, 56-61. [CrossRef] [PubMed]

69. Rexrode, K.M.; Pradhan, A.; Manson, J.E.; Buring, J.E.; Ridker, P.M. Relationship of total and abdominal adiposity with CRP and IL-6 in women. Ann. Epidemiol. 2003, 13, 674-682. [CrossRef]

70. Su, H.Y.; Lee, H.C.; Cheng, W.Y.; Huang, S.Y. A calorie-restriction diet supplemented with fish oil and high-protein powder is associated with reduced severity of metabolic syndrome in obese women. Eur. J. Clin. Nutr. 2015, 69, 322-328. [CrossRef] [PubMed]

71. Grossmann, R.E.; Tangpricha, V. Evaluation of vehicle substances on vitamin D bioavailability: A systematic review. Mol. Nutr. Food Res. 2010, 54, 1055-1061. [CrossRef] [PubMed]

72. Havers, F.P.; Detrick, B.; Cardoso, S.W.; Berendes, S.; Lama, J.R.; Sugandhavesa, P.; Mwelase, N.H.; Campbell, T.B.; Gupta, A.; ACTG A5175 PEARLS; et al. Change in vitamin D levels occurs early after antiretroviral therapy initiation and depends on treatment regimen in resource-limited settings. PLoS ONE 2014, 9, e95164. [CrossRef] [PubMed]

73. Shivakoti, R.; Yang, W.T.; Berendes, S.; Mwelase, N.; Kanyama, C.; Pillay, S.; Samaneka, W.; Santos, B.; Poongulali, S.; Tripathy, S.; et al. Persistently elevated C-reactive protein level in the first year of antiretroviral therapy, despite virologic suppression, is associated with HIV disease progression in resource-constrained settings. J. Infect. Dis. 2016, 213, 1074-1078. [CrossRef] [PubMed]

74. Bahrami, A.; Sadeghnia, H.R.; Tabatabaeizadeh, S.A.; Bahrami-Taghanaki, H.; Behboodi, N.; Esmaeili, H.; Ferns, G.A.; Mobarhan, M.G.; Avan, A. Genetic and epigenetic factors influencing vitamin D status. J. Cell. Physiol. 2017. [CrossRef] [PubMed]

(C) 2018 by the authors. Licensee MDPI, Basel, Switzerland. This article is an open access article distributed under the terms and conditions of the Creative Commons Attribution (CC BY) license (http:/ / creativecommons.org/licenses/by/4.0/). 